\title{
Characterization of Diaporthe spp. Associated With Spruce Decline on Colorado Blue Spruce in Michigan
}

\author{
Monique L. Sakalidis, ${ }^{1,2, \dagger}$ Carmen M. Medina-Mora, ${ }^{1}$ Keumchul Shin, ${ }^{1,3}$ and Dennis W. Fulbright ${ }^{1}$ \\ ${ }^{1}$ Department of Plant, Soil and Microbial Sciences, Michigan State University, East Lansing, MI 48824, U.S.A. \\ 2 Department of Forestry, Michigan State University, East Lansing, MI 48824, U.S.A. \\ ${ }^{3}$ Department of Forest Environmental Resources, Gyeongsang National University (Institute of Agriculture \& Life Science), Jinju 52828, \\ South Korea \\ Accepted for publication 28 August 2020.
}

\begin{abstract}
Since 2006 there has been a decline in Colorado blue spruce (CBS; Picea pungens) planted as landscape trees and for Christmas tree production throughout the Lower Peninsula of Michigan. This decline is characterized by a slow loss of needles in the lower portion of the tree starting at branch tips, followed by entire branch dieback, which progresses upward over several years. This dieback has been linked to shallow branch cankers visible in the phloem when the bark layer is removed. Isolates in the fungal genus Diaporthe have been consistently isolated from lesion margins on symptomatic branches. Before the initial reports of declining CBS in landscape and Christmas trees, Diaporthe was known only as a nursery disease of CBS. To determine the species of Diaporthe linked to the decline of CBS in Michigan, seven gene regions were sequenced from a collection of Diaporthe isolates collected in 2011
\end{abstract}

ABSTRACT through 2018 from CBS and other coniferous hosts. Subsequent phylogenetic analyses indicated that Diaporthe eres and a novel Diaporthe clade were present on symptomatic CBS in Michigan. The new species $D$. brevicancria nov. is described, and Koch's postulates were confirmed for $D$. brevicancria nov. and $D$. eres. D. brevicancria nov. produced the largest cankers in greenhouse pathogenicity trials, and dual inoculations of $D$. brevicancria nov. and $D$. eres produced intermediate cankers.

Keywords: analytical and theoretical plant pathology, conifer, disease control and pest management, etiology, multigene phylogeny, mycology, pathogenicity, Phomopsis, phylogenetics, Picea pungens, species description
Production of conifers, including spruce, has long been a mainstay of the nursery industry in Michigan. Conifer production makes up nearly $70 \%$ of the sales in tree nursery production in Michigan (MDARD and USDA NASS 2005). Michigan growers produce spruce seedlings and transplants for reforestation, conservation, and Christmas trees. Colorado blue spruce (CBS; Picea pungens) is the most popular Christmas tree spruce species sold for the live Christmas tree market or "cut and carry" (MDARD and USDA NASS 2005). Many Michigan nurseries also produce landscape-sized spruce trees for sale as balled-in-burlap or spadedug trees. Additionally, CBS and Norway spruce (P. abies) are two of the main species shaping urban and community forests in Michigan and the Midwest, ranking second to maple in abundance in the cities surveyed (Wade 2010).

In the 1970s and 1980s there was high demand for CBS in Michigan, where many trees were planted for home and roadside landscaping. These trees were chosen for their aesthetic appeal and ability to grow well in a variety of environments with minimal management. Since 2006, there has been a decline in mature spruce trees throughout the Lower Peninsula of Michigan (Fulbright et al.

†Corresponding author: M. L. Sakalidis; sakalidi@msu.edu

Funding: This study was financially supported by the Michigan Christmas Tree Association and by Michigan State University Extension, Michigan State University AgBioResearch, and the Michigan Department of Agriculture and Rural Development (through MSU Project GREEEN grant number GR17-052).

The fourth author, Dr. Dennis W. Fulbright, is deceased.

*The $\boldsymbol{e}$-Xtra logo stands for "electronic extra" and indicates that one supplementary table and 10 supplementary figures are published online.

The author(s) declare no conflict of interest.

C 2021 The American Phytopathological Society 2011a, b, 2012; McTavish et al. 2018). Spruce decline is noticeable as an initial loss of needles followed by branch dieback on the bottom north side of the tree. Over several years there is an upward progression of these symptoms, moving to the sunny side of the trees and to points where trees are not touching. The disease can progress into apical branches; however, crown mortality is rare. This may be because trees are often removed before this point, because one method of mitigating disease involves pruning out affected branches.

A systematic survey of trees, showing evidence of decline such as needle loss and branch dieback, demonstrated that declining CBS was found throughout the Lower Peninsula (McTavish et al. 2018). Historically, this decline was attributed to canker causing Cytospora spp. and several needle cast pathogens (Rhizosphaera kalkhoffii and Stigmina lautii) (Fulbright and O'Donnell 2011). Although needle cast diseases can cause needle loss and, in some cases, branch dieback, symptomatic trees did not always have detectable levels of needle cast disease. Instead, careful removal of the bark of symptomatic trees revealed nondescript, dry cankers present in the phloem, which were rarely visible when the bark was left intact (Fulbright et al. 2011a, b). Isolations made from the lesion margin of these cankers and completion of Koch's postulates demonstrated that Diaporthe spp. had the ability to cause cankers and associated branch dieback symptoms in CBS (McTavish et al. 2018). Diaporthe spp. were associated with these declining trees and were isolated from cankers on symptomatic CBS, white spruce (Picea glauca), Norway spruce, Douglas fir (Pseudotsuga menziesii), and arborvitae hedges (Thuja occidentalis). Subsequent pathogenicity trials revealed that among the spruce taxa, CBS is the most susceptible, followed by Norway spruce, white spruce, Black Hills spruce (Picea glauca 'Densata'), Serbian spruce (Picea omorika), and Meyer spruce (Picea meyeri) (McTavish et al. 2018).

Diaporthe Nitschke (anamorph Phomopsis [Sacc.] Bubák) is a large, globally distributed genus of saprophytic, pathogenic, and 
endophytic fungi that can colonize a broad range of hosts across both angiosperms and gymnosperms and spans crops, ornamentals, and forest trees (Boddy and Griffith 1989; Carroll 1986; Gomes et al. 2013; Huang et al. 2015; Rehner and Uecker 1994; Udayanga et al. 2011; Webber and Gibbs 1984). Diaporthe spp. are associated with stem cankers, leaf spots, blights, dieback, decay, wilt, and root and fruit rot diseases of a taxonomically diverse array of plant species (Butler et al. 2009; Fan et al. 2015; Freedman et al. 2016; Mostert et al. 2001; Santos et al. 2011; Santos and Phillips 2009; Thompson et al. 2011; Uecker 1988; van Rensburg et al. 2006). Recent revisions of taxonomy in Diaporthe (Santos et al. 2017; Udayanga et al. 2011) have relied on multigene analyses to distinguish between species (Dissanayake 2017; Udayanga et al. 2012, 2014a, b).

$D$. eres is a species complex of pathogenic opportunists, found mainly on woody plants in temperate regions of in Europe, Asia, New Zealand, and the United States (Anagnostakis 2007; Baumgartner et al. 2013; Thomidis and Michailides 2009; Udayanga et al. 2014a; Vrandečić et al. 2010). Recent efforts to characterize this complex and closely related species have relied on genealogical concordance between multiple gene regions (Udayanga et al. 2014a). D. eres was identified as one of the five genetic groups of Diaporthe involved in spruce decline in Michigan (McTavish et al. 2018). Species of Phomopsis are common anamorphs of Diaporthe and have been previously linked to symptomatic nursery (Igoe et al. 1995; Sanderson and Worf 1986) and landscape CBS (Sanderson and Worf 1986). It is unclear whether the $D$. eres or the remaining four genetic groups recently isolated from symptomatic landscape CBS (McTavish et al. 2018) were the same species associated with nursery and landscape CBS isolated approximately 30 years ago (Igoe et al. 1995; Sanderson and Worf 1986).

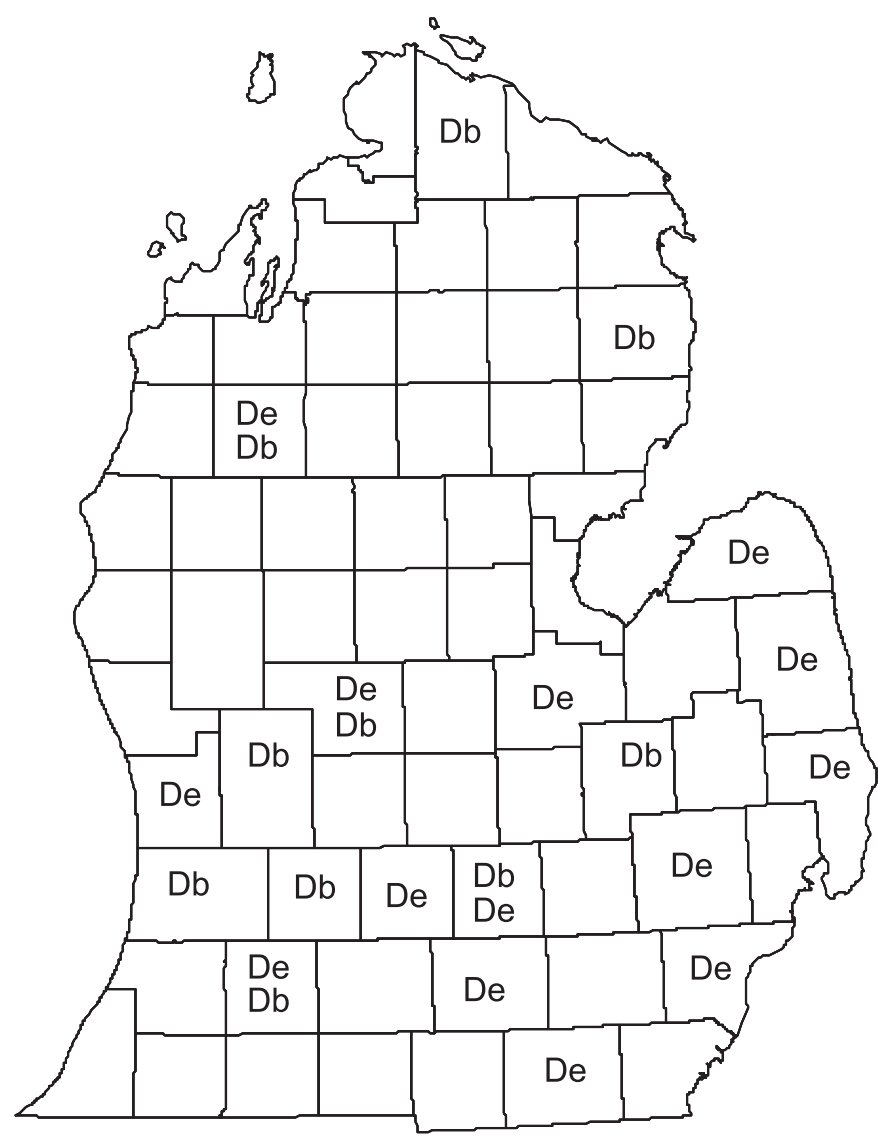

Fig. 1. Distribution of Diaporthe brevicancria nov. (Db) and Diaporthe eres (De) samples collected in the Lower Peninsula of Michigan, U.S.A.
To implement a sustainable management plan for a disease issue, an understanding of the pathogen biology, epidemiology, and diversity is advantageous. A first step in this process involves adequate identification of the causal agents of the disease. This involves the morphological, phenotypic, and molecular characterization of the isolates associated with symptomatic hosts. Five genetic groups of Diaporthe on CBS in Michigan were previously identified from the internal transcribed spacer (ITSrDNA) and betatubulin (TUB) gene regions (McTavish et al. 2018). However, species designation in $D$. eres and closely related species requires a multigene phylogenetic approach, and typical DNA barcoding genes such as the ITSrDNA region have been shown to overestimate the species among this group (Udayanga et al. 2014a). We hypothesized that multiple Diaporthe spp. are involved in the decline of CBS in Michigan; however, their relative contribution to disease development and interaction with each other was unknown. To designate a specific epithet (of either a known or a new species) for the isolates associated with declining spruce in Michigan, the sequencing of additional gene regions was necessary. Additional morphological and phenotypic characterization of the genetic groups identified in our molecular analyses was completed to assess the contribution of these genetic groups to disease development in CBS. Finally, we evaluated the distribution of these two species on CBS in Michigan and examined their interaction both individually and together in planta.

\section{MATERIALS AND METHODS}

Origin and identity of isolates. Forty-two single spore isolates were collected from Colorado blue spruce (Picea pungens) and other woody trees from across the Lower Peninsula of Michigan (Fig. 1) from 2011 to 2018, and when known, host species and geographic location are listed in Table 1 and Supplementary Table S1. Cultures of all Michigan isolates are stored in $40 \%$ glycerol or sterile distilled water and maintained at room temperature (approximately $22^{\circ} \mathrm{C}$ ) in the Forest Pathology laboratory at Michigan State University.

DNA extraction, PCR amplification, and sequencing. To assign Michigan isolates to a species, the elongation factor alpha region was amplified for all 42 isolates, because this region is considered the most informative for the $D$. eres species complex (Udayanga et al. 2014a). Amplification of six additional gene regions for the multigene phylogenetic analysis was performed with three representative Michigan isolates of D. eres (MIFCC 306, MIFCC 316, and MIFCC 320) and of D. brevicancria nov. (MIFCC 305, MIFCC 308, and MIFCC 313). The partial sequences of actin (ACT), DNA-lyase (Apn2), calmodulin (CAL), histone-3 (HIS), TUB, and ITSrDNA were all amplified (Table 2). Sequence data of the ex-type isolates of Diaporthe species and other representative isolates of each species were retrieved from GenBank, and an additional sequence of $D$. maritima was generated by amplifying ACT, CAL, and HIS gene regions of isolate DACM250563 (Table 1). Single conidial isolates were grown on potato dextrose agar (39 $\mathrm{g}$ of PDA in 1 liter of distilled water; Difco PDA, Sparks, MD) overlaid with a disc of sterile cellophane for 7 days at room temperature (approximately $20^{\circ} \mathrm{C}$ ). For each isolate, the mycelial mass was harvested and placed into $1.5 \mathrm{ml}$ of sterile Eppendorf tubes, and DNA was extracted with the DNeasy Plant Mini Kit (Qiagen, Valencia, CA) according to the manufacturer's protocol with the exception of $2 \%$ cetrimonium bromide buffer (Hamelin et al. 2000) as the extraction solution.

PCRs were carried out in an ABI 2720 thermocycler (Applied Biosystems, Foster City, CA). The PCR mixture contained $5 \mu \mathrm{l}$ of $5 \times$ colorless buffer (Promega Corp., Madison, WI), $4 \mu \mathrm{l}$ of $\mathrm{Mg}^{2+}$ (25 mM) (Promega), $0.5 \mu \mathrm{l}$ of dNTP (100 mM) (Invitrogen, Carlsbad, CA), $1.0 \mu \mathrm{l}$ of each primer $(10 \mathrm{mM})$, and $0.13 \mu \mathrm{l}$ of GoTaq Flexi (Promega; $5 \mathrm{U} / \mu \mathrm{l}$ ) and DNA (50 $\mathrm{ng} / \mu \mathrm{l})$, and the PCR total volume was adjusted with PCR-grade water to a final volume of $25 \mu$ l. PCRs, with the exception of ITSrDNA primer pairs, were run 
TABLE 1. Diaporthe species used in this study

\begin{tabular}{|c|c|c|c|c|c|c|}
\hline Species & Isolate code & Date $^{a}$ & Collected by & Host $^{\mathrm{a}}$ & Location & $\begin{array}{l}\text { Michigan } \\
\text { habitat }^{\mathrm{b}}\end{array}$ \\
\hline \multicolumn{7}{|l|}{ Diaporthe brevicancria } \\
\hline \multirow[t]{21}{*}{ nov. } & MIFCC 321 & 2013 & C. McTavish & - & USA & $\mathrm{C}$ \\
\hline & MIFCC 322 & 2013 & C. McTavish & - & USA & $\mathrm{C}$ \\
\hline & MIFCC 323 & 2013 & C. McTavish & - & USA & $\mathrm{C}$ \\
\hline & MIFCC 308 & 2012 & S. Stadt & Picea pungens & USA & $\mathrm{L}$ \\
\hline & MIFCC 324 & 2013 & C. McTavish & - & USA & $\mathrm{C}$ \\
\hline & MIFCC 300 & 2011 & S. Stadt & P. pungens & USA & $\mathrm{L}$ \\
\hline & MIFCC 301 & 2011 & S. Stadt & P. pungens & USA & $\mathrm{L}$ \\
\hline & MIFCC 302 & 2011 & S. Stadt & $P$. pungens & USA & - \\
\hline & MIFCC 303 & 2011 & S. Stadt & Picea glauca & USA & - \\
\hline & MIFCC 309 & 2012 & S. Stadt & Picea abies & USA & $\mathrm{L}$ \\
\hline & MIFCC 304 & 2011 & S. Stadt & P. pungens & USA & $\mathrm{C}$ \\
\hline & MIFCC 310 & 2012 & S. Stadt & $P$. pungens & USA & $\mathrm{C}$ \\
\hline & MIFCC 311 & 2012 & S. Stadt & $P$. pungens & USA & $\mathrm{N}$ \\
\hline & MIFCC 325 & 2013 & C. McTavish & - & USA & $\mathrm{C}$ \\
\hline & MIFCC 326 & 2013 & C. McTavish & - & USA & $\mathrm{C}$ \\
\hline & MIFCC 312 & 2012 & S. Stadt & P. pungens & USA & $\mathrm{C}$ \\
\hline & MIFCC 305 & 2011 & S. Stadt & P. glauca & USA & $\mathrm{N}$ \\
\hline & $\begin{array}{c}\text { MIFCC } 313^{\mathrm{c}} / \mathrm{CBS} \\
146962\end{array}$ & 2012 & S. Stadt & $P$. pungens & USA & $\mathrm{N}$ \\
\hline & MIFCC 314 & 2012 & J. Byrne & P. pungens & USA & $\mathrm{N}$ \\
\hline & MIFCC $338^{d}$ & 2018 & K. Shin & - & USA & $\mathrm{L}$ \\
\hline & MIFCC $340^{\mathrm{d}}$ & 2018 & K. Shin & - & USA & $\mathrm{L}$ \\
\hline \multirow[t]{28}{*}{ Diaporthe eres } & MIFCC 327 & 2013 & C. McTavish & - & USA & $\mathrm{C}$ \\
\hline & MIFCC 328 & 2013 & C. McTavish & - & USA & $\mathrm{C}$ \\
\hline & MIFCC 329 & 2013 & C. McTavish & - & USA & $\mathrm{C}$ \\
\hline & MIFCC 330 & 2013 & C. McTavish & - & USA & $\mathrm{C}$ \\
\hline & MIFCC 331 & 2013 & C. McTavish & - & USA & $\mathrm{C}$ \\
\hline & MIFCC 332 & 2013 & C. McTavish & - & USA & $\mathrm{C}$ \\
\hline & MIFCC 315 & 2012 & S. Stadt & Pseudotsuga menziesii & USA & $\mathrm{L}$ \\
\hline & MIFCC 333 & 2013 & C. McTavish & - & USA & $\mathrm{C}$ \\
\hline & MIFCC 334 & 2013 & C. McTavish & - & USA & $\mathrm{C}$ \\
\hline & MIFCC 335 & 2013 & C. McTavish & - & USA & $\mathrm{C}$ \\
\hline & MIFCC 336 & 2013 & C. McTavish & - & USA & $\mathrm{C}$ \\
\hline & MIFCC $337^{d}$ & 2018 & K. Shin & - & USA & $\mathrm{L}$ \\
\hline & MIFCC $339^{d}$ & 2018 & K. Shin & - & USA & $\mathrm{L}$ \\
\hline & MIFCC $341^{d}$ & 2018 & K. Shin & - & USA & $\mathrm{L}$ \\
\hline & MIFCC 306 & 2011 & S. Stadt & Thuja occidentalis & USA & $\mathrm{L}$ \\
\hline & MIFCC 316 & 2012 & S. Stadt & P. pungens & USA & $\mathrm{C}$ \\
\hline & MIFCC 307 & 2011 & S. Stadt & P. glauca & USA & $\mathrm{C}$ \\
\hline & MIFCC 317 & 2012 & S. Stadt & P. pungens & USA & $\mathrm{N}$ \\
\hline & MIFCC 318 & 2012 & S. Stadt & $P$. pungens & USA & $\mathrm{N}$ \\
\hline & MIFCC 319 & 2012 & S. Stadt & $P$. pungens & USA & $\mathrm{N}$ \\
\hline & MIFCC 320 & 2012 & S. Stadt & $P$. pungens & USA & $\mathrm{L}$ \\
\hline & CBS $138594^{\mathrm{c}}$ & - & R. Schumacher & Ulmus laevis & Germany & - \\
\hline & CBS 113470 & - & K. Seifert & Castanea sativa & Australia & - \\
\hline & CBS 587.79 & - & G. H. Boerema & Pinus parviflora var. pentaphylla & Japan & - \\
\hline & CBS $439.82^{c}$ & - & H. Butin & Cotoneaster sp. & United Kingdom & - \\
\hline & AR3671 & - & S. Kanematsu & Pyrus pyrifolia & Japan & - \\
\hline & DNP128 & - & S. X. Jiang & Castanea mollissima & China & - \\
\hline & DPO177 & - & W. Kandula & Pyrus pyrifolia & New Zealand & - \\
\hline Diaporthe alleghaniensis & CBS $495.72^{c}$ & - & R. H. Arnold & Betula alleghaniensis & Canada & - \\
\hline \multirow[t]{4}{*}{ Diaporthe alnea } & CBS 159.47 & - & S. Truter & Alnus sp. & Netherlands & - \\
\hline & CBS $146.46^{\mathrm{c}}$ & - & S. Truter & Alnus sp. & Netherlands & - \\
\hline & LCM $22 b .02 a$ & - & L. Mejia & Alnus sp. & USA & - \\
\hline & LCM $22 b .02 b$ & - & L. Mejia & Alnus sp. & USA & - \\
\hline Diaporthe bicinta & CBS $121004^{c}$ & - & L. Vasilyeva & Juglans sp. & USA & - \\
\hline & CBS $139.27^{\mathrm{c}}$ & - & L. E. Wehmeyer & Celastrus scandens & USA & - \\
\hline \multirow[t]{2}{*}{ Diaporthe citrichinensis } & CBS 134242 & - & F. Huang & Citrus sp. & China & - \\
\hline & & & F. Huang & Citrus sp. & China & - \\
\hline Diaporthe citri & CBS 135422 & - & L. Timmer & Citrus sp. & USA & - \\
\hline Diaporthe helicis & CBS $138596^{\mathrm{c}}$ & - & R. Schumacher & Hedera helix & Germany & - \\
\hline Diaporthe maritima & NB365-71I & - & J. B. Tanney & Picea rubens & Canada & - \\
\hline Diaporthe neilliae & CBS 144.27 & - & L. E. Wehmeyer & Spiraea sp. & USA & - \\
\hline Diaporthe pulla & CBS $338.89^{c}$ & - & M. Cevetcovic & Hedera helix & Yugoslavia & - \\
\hline \multirow[t]{5}{*}{ Diaporthe vaccinii } & CBS 135436 & - & D. Farr & Vaccinium corymbosum & USA & - \\
\hline & FAU633 & - & F. Uecker & Vaccinium sp. & USA & - \\
\hline & FAU446 & - & F. Caruso & Vaccinium macrocarpon & USA & - \\
\hline & CBS $160.32^{c}$ & - & C. Shear & Oxycoccus macrocarpos & USA & - \\
\hline & FAU468 & - & F. Uecker & $\begin{array}{c}\text { Vaccinium macrocarpon cultivar } \\
\text { Wilcox }\end{array}$ & USA & - \\
\hline
\end{tabular}

a Dashes indicate data are not available.

b $\mathrm{C}$, abandoned Christmas tree plantation; L, landscape; and N, nursery.

c Sequence obtained from ex-type, epi-type, or holotype isolate.

d Collected from the same individual tree. 
in the following thermal cycling conditions: initial denaturation at $95^{\circ} \mathrm{C}$ for $2 \mathrm{~min}$, then 40 cycles of $95^{\circ} \mathrm{C}$ for $30 \mathrm{~s}, 55^{\circ} \mathrm{C}$ for $50 \mathrm{~s}$, and $72^{\circ} \mathrm{C}$ for $1 \mathrm{~min}$, and a final extension of $72^{\circ} \mathrm{C}$ for $5 \mathrm{~min}$ with a holding temperature at $4^{\circ} \mathrm{C}$. PCR conditions were the same for all genes, with the exception of the addition of 5.6\% dimethyl sulfoxide ( $\mathrm{vol} / \mathrm{vol}$ ) for the HIS gene (Table 2), and for the ITSrDNA gene region, PCR conditions were modified as follows: PCR denaturation temperature was reduced to $94^{\circ} \mathrm{C}$, and annealing temperature was held at $55^{\circ} \mathrm{C}$ for $45 \mathrm{~s}$ for 35 cycles instead of 40 cycles. PCR products were visualized by $0.75 \%$ agarose gel electrophoresis.

PCR products were purified with a Qiagen PCR purification kit (Qiagen, Valencia, CA) according to the manufacturer's recommendations and sequenced by the Michigan State University (MSU) Research Technology Support Facility (Michigan State University, https://rtsf.natsci.msu.edu/) on an ABI 3730xl platform (Applied Biosystems, Foster City, CA) or by Macrogen Corporation USA (https://psomagen.com/) with Next Generation Sequencing technology (Macrogen, Rockville, MD). Forward and reverse sequences of each region sequence were aligned and manually edited in Geneious Pro (version 10.2.3), created by Biomatters (available from http://www.geneious.com/), and the online alignment program M-Coffee (Di Tommaso et al. 2011; Moretti et al. 2007; Notredame et al. 2000; Wallace et al. 2006) (available from http:// tcoffee.crg.cat/apps/tcoffee/do:mcoffee).

Phylogenetic analyses. Phylogenetic relationships between isolates were determined for seven individual gene regions (ACT, Apn2, CAL, EF1- $\alpha$, HIS, ITSrDNA, and TUB) and for a concatenated multigene analysis including all gene regions except ITSrDNA. ITSrDNA was excluded because this region is not considered informative for the $D$. eres species complex (Udayanga et al. 2014a). However, we amplified the ITSrDNA gene region because it is a standard DNA barcoding gene region for fungi and is a traditional first step in using DNA sequence-based methods for fungal species identification. Phylogenetic trees were visualized in TreeGraph 2 (Stöver and Müller 2010; available from http://treegraph.bioinfweb.info/). The maximum likelihood (ML) tree is presented here with clades supported by $\geq 70 \%$ bootstrap and with posterior probabilities $\geq 0.75$ considered significant. GenBank accession numbers are available in Supplementary Table S1.

Phylogenetic reconstructions of concatenated and individual gene trees were performed via maximum parsimony (MP) implemented in PAUP (version 4.0a build 163) (Swofford 2002), ML implemented in RAxML (version 8.2.11) (Stamatakis 2014), and Bayesian Markov chain Monte Carlo (MCMC) criteria implemented in MrBayes (version 3.2.6) (Ronquist et al. 2012). RAxML (Stamatakis 2014) was run on XSEDE in the CIPRES Science Gateway platform (Miller et al. 2010).
For the MP analyses, gaps were treated as a fifth character, and all characters were unordered and of equal weight. The most parsimonious trees were found via heuristic searches, stepwise addition, and tree bisection and reconstruction and the branchswapping algorithm. Maxtrees were unlimited; branches were collapsed if maximum length was zero. Uninformative characters were excluded from analysis. One thousand bootstrap replicates (Felsenstein 1985) were performed to assess the support for branching, and sequences of $D$. citri (CBS135422) were used as the outgroup. Estimated levels of homoplasy and phylogenetic signal (retention and consistency indices and g1-value) (Hillis and Huelsenbeck 1992) were also determined by in PAUP.

For the ML analyses, the best-scoring gene trees were estimated under the GTR + GAMMA evolutionary model with 1,000 bootstrap replicates generated via the rapid bootstrapping algorithm in a single run (trees were generated via the following command: raxmlHPC-HYBRID -T 4 -n result -s infile.txt -m GTRGAMMA -p 17042018 -f a -N 1000 -x 17042018). There was no correction for ascertainment bias. Bootstrap support values were added to the bestscoring ML tree.

Before the Bayesian analyses were run, jModelTest2 (version 2.1.6) (Darriba et al. 2012; Guindon and Gascuel 2003) on XSEDE in the CIPRES Science Gateway platform (Miller et al. 2010) was used to determine the best nucleotide substitution model via the Akaike information criterion, corrected for small sample size, to ensure the model could be run in MrBayes. The number of substitution schemes was set at 3 .

Bayesian analyses were performed by applying the HKY $(+\mathrm{G} /+\mathrm{I})$ or K80 substitution models to each gene region (Table 3), with all model parameters allowed to be estimated by MrBayes. The Markov chain Monte Carlo analysis of four chains started from random tree topology and lasted 1,000,000 generations. Trees were saved every 100 generations. Burn-in was set at $25 \%$, and the $50 \%$ majority rule consensus tree and posterior probabilities were calculated from the remaining trees.

Pathogenicity. Thirty-five 4-year-old 2-2 (2 years in a seed bed, 2 years in a transplant bed) CBS seedlings, with a mean $10.5 \mathrm{~mm}$ stem diameter at $5 \mathrm{~cm}$ above the soil line, were potted in 25-cm-diameter tapered terra cotta pots containing soilless media (media mix of peat, perlite, wetting agents, and starting nutrients; Suremix Perlite, Michigan Grower Products, Inc., Galesburg, MI). Seedlings were hand watered twice a week for the duration of the pathogenicity trials. Seedlings were grown on a bench in a greenhouse where the temperatures during the pathogenicity trials ranged from 22 to $32^{\circ} \mathrm{C}$ (mean $26^{\circ} \mathrm{C}$ ), measured with a $\mathrm{HOBO}$ UX100 data logger (Onset Computer Corporation, Bourne, MA). The greenhouse was sprayed with pesticides at the recommended rates to avoid cockroaches and other insects in nearby crops

TABLE 2. PCR primers of conserved gene regions (actin [ACT], DNA-lyase [Apn2], calmodulin [CAL], elongation factor 1-alpha [EF1- $\alpha$ ], histone-3 [HIS], betatubulin [TUB], and the internal transcribed spacer region [ITSrDNA]) used in this study to characterize Diaporthe species

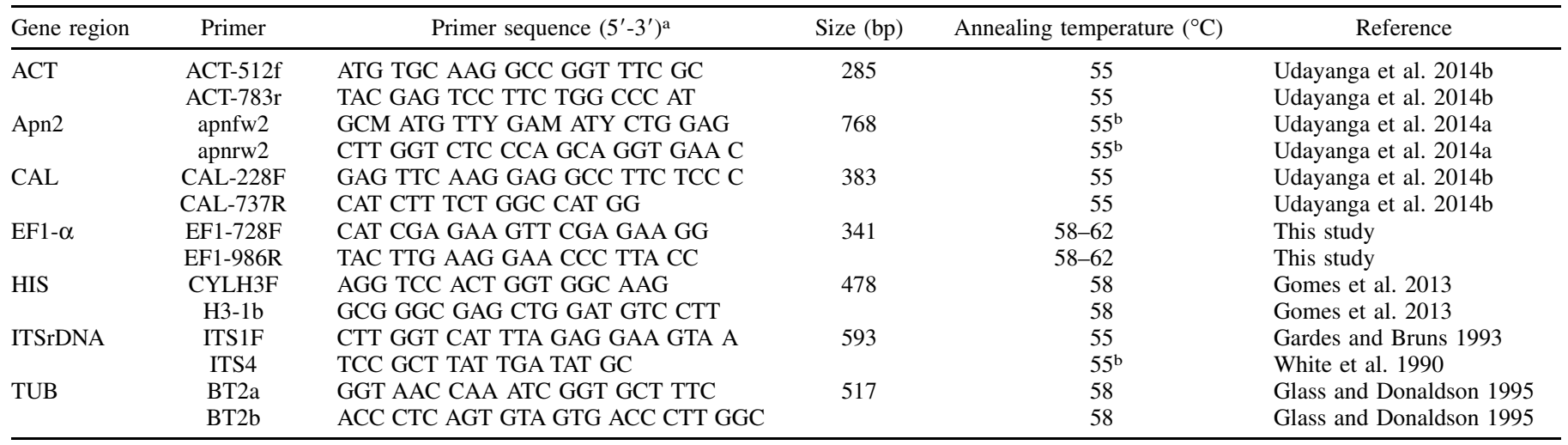

a Alternative bases used: $\mathrm{M}$, adenosine or cytosine; Y, cytosine or thymine.

${ }^{\mathrm{b}}$ Indicates modification from original reference listed. 
growing in the same greenhouse, but no pesticides were applied at the soil or foliar level on any of the CBS seedlings used in this study. Two pathogenicity trials were run, the first for 12 weeks (October 2017 to January 2018) and the second for 5 weeks (January to February 2018).

Seedlings were arranged in a randomized complete block design with five replications containing seven inoculation treatments. Five seedlings were inoculated with four single isolates of $D$. eres (MIFCC 316 and MIFCC 320) and D. brevicancria nov. (MIFCC 305 and MIFCC 313), two dual inoculations (two isolates were placed into the same incision) with isolates MIFCC $305+$ MIFCC 320 and MIFCC $313+$ MIFCC 316, and a noninoculated control treatment. All isolates of D. eres (MIFCC 316 and MIFCC 320) and D. brevicancria nov. (MIFCC 305 and MIFCC 313) were grown on PDA media amended with streptomycin and ampicillin for 7 to 10 days at room temperature. In the first pathogenicity trial, a single lateral incision, separating the bark from the cambium, was made 5 to $10 \mathrm{~cm}$ above the soil surface. The plants were inoculated by placing a PDA plug $(6 \mathrm{~mm})$ colonized with mycelia or sterile PDA (as negative control) facing on the cambial region under the bark. Two halves of the plug from each isolate were added to the same incision for the dual inoculation treatments (MIFCC $305+$ MIFCC 320 and MIFCC 313 + MIFCC 316). The incisions were then wrapped with Parafilm (Denville Scientific, Holliston, MA). In the second trial, to decrease the length of the experiment, we increased the dosage of material used for inoculations through the use of two inoculation points, effectively doubling the amount of fungal or control material that was introduced into each seedling. Two separate incisions were made on each seedling, then inoculum was introduced as described for the single-incision experiment. To reduce the risk of lesions from each inoculation point overlapping, symptoms were recorded, and lesion sizes were measured after 5 weeks (second trial) instead of the 12 weeks used in the first trial. Lesions were uncovered by careful removal of the outer layer of bark to measure canker development. After the bark was removed, the stems were wrapped with a transparent film where the lesion was traced with a black permanent marker. Marked areas were scanned with a WorkForce Pro WF-4630 scanner (Epson America Inc., Long Beach, CA). The scanned image files were measured with ImageJ. The original images were converted to grayscale ( $8 \mathrm{bit}$ ), and the measurement scale was set after a known distance of marked areas on the image files was measured to determine the length of a pixel. A threshold of the lesion area was used with the automated routine (binary) to determine the black marked areas. Lesion areas $\left(\mathrm{mm}^{2}\right)$ of the black marked portion were calculated as the total number of pixels multiplied by a distance of a pixel, which were converted to the relative lesion area per stem diameter $(\mathrm{mm})$. Koch's postulates were confirmed by reisolating $D$. eres and $D$. brevicancria nov. from the inoculation sites of the single and dual inoculations onto PDA media amended with streptomycin and ampicillin. The identity of each reisolate was confirmed on the basis of morphological characteristics.

Data analyses were carried out according to the general linear model procedure of SAS version 9.4 (SAS Institute Inc., Cary, NC) to test for significant effects of the pathogen inoculation treatments, blocks, experimental trials, and all interactions on canker development. All residuals were checked for normality with the ShapiroWilk test, and data were log-transformed if needed to obtain normality, and homogeneity of variances across treatments was evaluated with Levene's test. The lesion means were compared between Diaporthe species and between isolates via one-way analysis of variance followed by Tukey's honestly significant difference tests to separate significantly different means. Correlation between lesions and stem diameter was determined by regression analysis in Excel Office 365 (Microsoft Corporation, Redmond, WA). Statistical significance was considered at $P<0.05$.

Morphology. For pycnidia formation, the mycelia of representative isolates of $D$. brevicancria nov., D. eres, and D. maritima were subcultured onto a combination of the following media and plant tissues: individual PDA plates; $2 \%$ malt extract agar (double di-ionized water containing $20 \mathrm{~g} /$ liter of malt extract and $20 \mathrm{~g} / \mathrm{liter}$ of agar; Difco, Sparks, MD); sterilized, excised spruce branches $3.8 \mathrm{~cm}$ in length; and sterile spruce needles embedded onto $1.8 \%$ water agar (WA; Bacto agar; Difco, Sparks, MD, dissolved in double di-ionized water). Plates were incubated at room temperature (approximately $22^{\circ} \mathrm{C}$ ) for 14 to 30 days under $18 \mathrm{~h}$ light and $6 \mathrm{~h}$ dark cycles. Observations of pycnidia were performed under a Leica S8APO microscope, and digital images were acquired with a Leica MC150 HD. Observations of conidiogenous cells, phialides, and asexual spores were performed under a Leica DM750 microscope with integrated camera Leica ICC50W. Measurements of asexual spores (alpha conidia and beta conidia) were made with a Leica LAS X software measurement module (version 4.9.0; Leica Microsystems Inc., Buffalo Grove, IL). Measurements of pycnidia, phialides, and asexual spores were based on 30, 30, and 50 observations, respectively. Observations of conidiogenous cells were recorded for the holotype of $D$. brevicancria nov. (CBS 146962). Differential interference contrast images were obtained for unstained and fixed (10\% formalin) pycnidia embedded on paraffin with a Nikon C2 with confocal laser scanning microscopy (Nikon Instruments Inc. Melville, NY). Scanning electron microcopy images were obtained for pycnidia stained with $0.5 \mu \mathrm{m}$ osmium tetroxide with a JEOL 6610LV microscope (JEOL USA, Peabody, MA).

Culture morphology observations were made from colonies grown on PDA and incubated at $22^{\circ} \mathrm{C}$ for 14 days. Color of mycelia

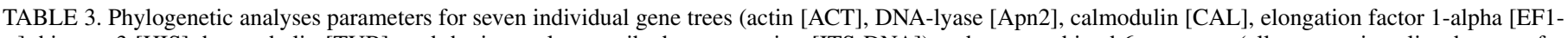

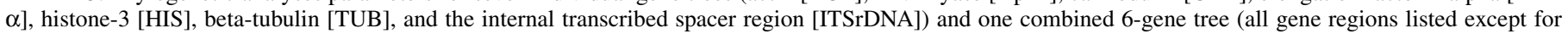
ITSrDNA)

\begin{tabular}{|c|c|c|c|c|c|c|c|c|c|}
\hline Analysis & ACT & Apn2 & CAL & EF1- $\alpha$ & EF1- $\alpha-68$ & HIS & ITSrDNA & TUB & 6 gene \\
\hline \multicolumn{10}{|l|}{ Bayesian analyses } \\
\hline Nucleotide substitution model & $\mathrm{HKY}+\mathrm{G}$ & $\mathrm{HKY}+\mathrm{G}$ & K80 & $\mathrm{HKY}+\mathrm{G}$ & $\mathrm{HKY}+\mathrm{G}$ & $\mathrm{HKY}+\mathrm{I}$ & $\mathrm{HKY}+\mathrm{I}$ & $\mathrm{HKY}+\mathrm{I}$ & NA \\
\hline$-\operatorname{lnL}$ of model & 704.2123 & 2061.0987 & 956.989 & 1287.3522 & 1307.10894 & 1336.6432 & 1247.9716 & 1159.8259 & \\
\hline \multicolumn{10}{|l|}{ Maximum parsimony analyses } \\
\hline Total number of characters & 244 & 768 & 381 & 369 & 369 & 480 & 464 & 430 & 2,672 \\
\hline Number of included characters & 40 & 87 & 39 & 83 & 84 & 62 & 51 & 49 & 360 \\
\hline Number of excluded characters & 204 & 681 & 342 & 286 & 285 & 418 & 413 & 381 & 2,312 \\
\hline g1 & -0.911135 & -1.482265 & -1.712523 & -0.605689 & -0.324392 & -0.372126 & -0.440772 & -0.789535 & -0.745263 \\
\hline $\mathrm{CI}$ & 0.886792 & 0.843478 & 0.97561 & 0.791667 & 0.780488 & 0.754902 & 0.626168 & 0.931034 & 0.676568 \\
\hline $\mathrm{H} 1$ & 0.113208 & 0.156522 & 0.02439 & 0.208333 & 0.219512 & 0.245098 & 0.373832 & 0.068966 & 0.323432 \\
\hline RI & 0.965517 & 0.935714 & 0.990741 & 0.932249 & 0.962291 & 0.935897 & 0.882698 & 0.975758 & 0.868102 \\
\hline Length & 53 & 115 & 41 & 120 & 123 & 102 & 107 & 58 & 606 \\
\hline Number of trees & 7 & 1 & 1 & 2 & 10 & 90 & 27 & 2 & 12 \\
\hline Minimum length & 47 & 97 & 40 & 95 & 96 & 77 & 67 & 54 & 410 \\
\hline Maximum length & 221 & 377 & 148 & 464 & 812 & 467 & 408 & 219 & 1,896 \\
\hline
\end{tabular}


in culture was determined according to the Munsell soil color chart (Kollmorgen Instruments Corporation, New Windsor, NY), where the notation of color is written in the order of hue, value, and chroma. The optimal temperature for colony growth was determined from cultures grown on PDA incubated at $4^{\circ} \mathrm{C}$ and 10 to $40^{\circ} \mathrm{C}$ (at $5^{\circ} \mathrm{C}$ intervals). For colony growth, mycelial plugs $(6 \mathrm{~mm})$ obtained from the margin of actively growing colonies of three isolates of D. eres (MIFCC 306, MIFCC 316, and MIFCC 320) and three isolates of D. brevicancria nov. (MIFCC 305, MIFCC 308, and MIFCC 313) were placed on the center of PDA media. Three replicated Petri plates $(100 \mathrm{~mm} \times 15 \mathrm{~mm})$ were made of each isolate and arranged in a completely randomized design. Colony growth areas marked on each plate were scanned and measured manually in ImageJ (Abramoff et al. 2004; available at https://imagej.nih.gov/ij/), 5 days after incubation in the dark and before mycelia of at least one isolate reached the edge of a Petri plate. Mean colony growth areas $\left(\mathrm{mm}^{2}\right)$ were obtained for each isolate of two Diaporthe species at each temperature and subjected to one-way analysis of variance followed by Tukey's honestly significant difference tests to separate the means of data.

\section{RESULTS}

Phylogenetic analyses. Trimmed sequences of approximately $285 \mathrm{bp}$ for ACT, $768 \mathrm{bp}$ for Apn2, $383 \mathrm{bp}$ for CAL, $341 \mathrm{bp}$ for EF1$\alpha, 476 \mathrm{bp}$ for HIS, $593 \mathrm{bp}$ for ITSrDNA, and $517 \mathrm{bp}$ for TUB were obtained from all isolates. The final concatenated multigene

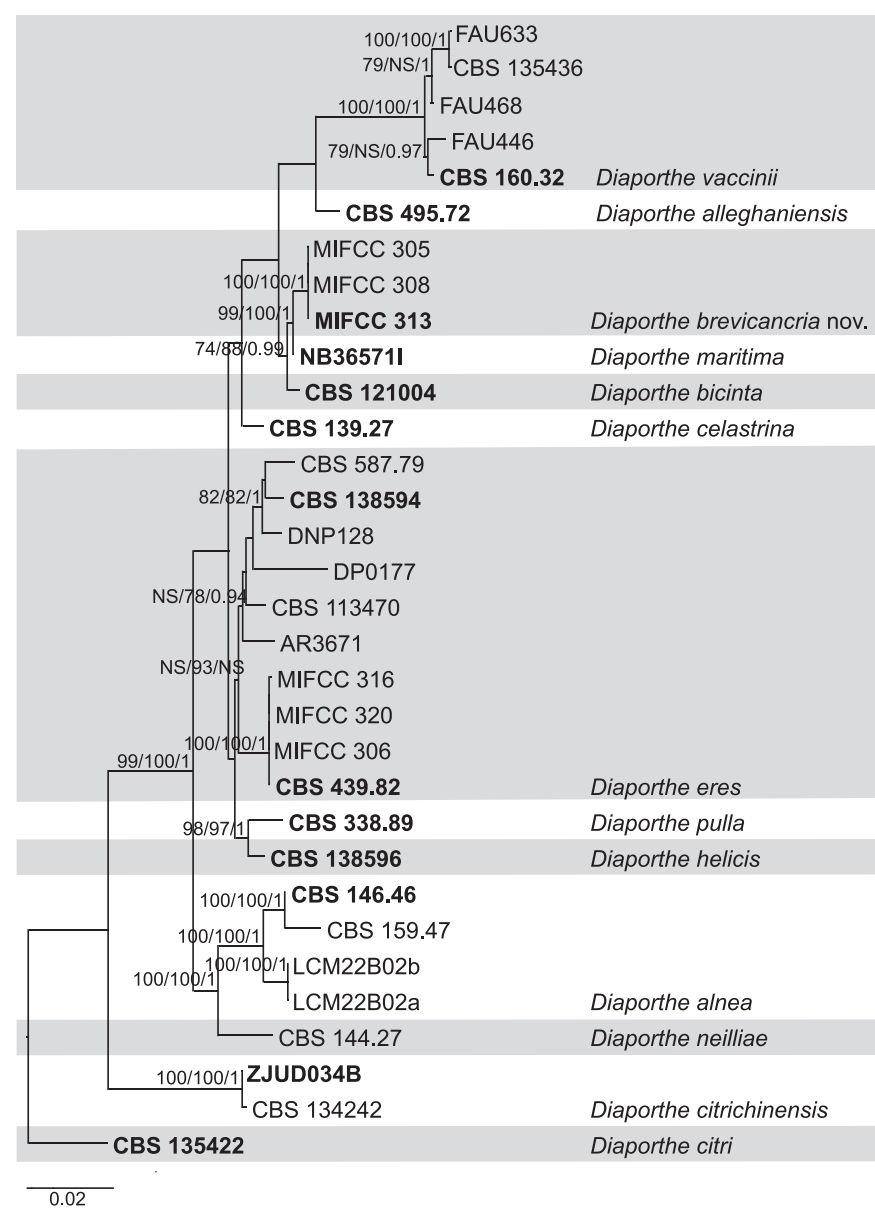

Fig. 2. Combined 6-gene maximum likelihood (ML) phylogram of Diaporthe species. Statistical support for the topology is presented when $\geq 70 \%$ for bootstrap values (ML, and maximum parsimony) and posterior probabilities are $\geq 0.75$ (Bayesian). NS indicates there was no support or insufficient support. The tree is rooted with Diaporthe citri (CBS 135422). Bold typeface indicates an ex-type, epi-type, or holotype isolate. alignment of six gene regions (all genes except for ITSrDNA) contained a total of 2,674 characters (Table 3). Bootstrap and posterior probabilities produced strong support for 13 clades that corresponded to described or proposed monophyletic species with the exception of $D$. eres, which contains multiple well-supported clades, typical of a species complex. D. brevicancria nov. is supported as a distinct species, separate from its sister species $D$. maritima and the closely related D. bicincta. Bayesian, ML, and MP analyses produced slightly different tree topologies. However, the overall separation of all species was maintained in the combined gene analysis (Fig. 2). Individual gene sets varied in their ability to delineate species. All gene regions except for CAL could delineate D. brevicancria nov. from all other described species (Supplementary Figs. S1 to S7).

Distribution of Diaporthe in Michigan. Both D. eres and D. brevicancria nov. have been detected from symptomatic conifers throughout the lower peninsula of Michigan (Fig. 1, Table 1, Supplementary Fig. S8, and Supplementary Table S1). D. eres has been isolated from cankered tissue on four host species: P. pungens, P. glauca, P. menziesii, and Thuja occidentalis (northern white cedar or eastern arborvitae). D. brevicancria nov. has been isolated from cankered tissue on three host species: P. pungens, Picea glauca 'Densata,' and P. abies. There was a single occurrence of both species being isolated from the same individual tree but never from the same canker (Table 1). Both species have been isolated from trees in nursery, landscape, and abandoned Christmas tree plantations.

Pathogenicity. One month after inoculation, symptoms close to the inoculation point, such as needle chlorosis and loss, and branch dieback were observed in the CBS seedlings inoculated with D. brevicancria nov. isolates MIFCC 305 and MIFCC 313 (Fig. 3A). Additionally, a sunken area with black pycnidia on the stem surface was visible around the inoculation point (Fig. 4A). After the epidermal layers were peeled off, necrotic lesions were evident as a darkening of vascular tissue upward and downward from the inoculation point in the CBS seedlings inoculated with $D$. brevicancria nov. and dual $D$. eres $+D$. brevicancria nov. inoculations. Small necrotic lesions were observed in the CBS seedlings inoculated with isolates MIFCC 316 and MIFCC 320 of D. eres. However, a sunken area and black pycnidia were not evident on the surface. Needle loss and branch dieback symptoms were rarely observed in the $D$. eres inoculated seedlings. Canker development and other visual symptoms were not observed in any of the five control seedlings (Fig. 3A, B, and C). Koch's postulates were completed as fungi with a colony morphology consistent with Diaporthe spp. were isolated from the margin of stem lesions.

There were significant differences in lesion area $(P<0.0001)$ in the two pathogenicity trials. Lesions were generally larger in the second trial, which contained twice the amount of fungal inoculum as in the first trial. Because a significant interaction between the two trials and inoculum dosage was detected $(P=0.016)$, the data from each trial were analyzed separately. According to Tukey's honestly significant difference test, there were no significant differences between the isolates of each Diaporthe species in the first (D. eres, $P=0.434$ and $D$. brevicancria nov., $P=0.982$ ) and second (D. eres, $P=0.122$ and $D$. brevicancria nov., $P=0.965)$ trials, respectively. Therefore, data from isolates of the same species were combined. The relative mean lesion area $\left(\mathrm{mm}^{2}\right)$ per stem diameter $(\mathrm{mm})$ were significantly affected by the Diaporthe species in trial 1 and $2(P<$ $0.0001)$. D. brevicancria nov. was the most virulent species, with a relative mean lesion area of 91.28 (trial 1) and $165.69 \mathrm{~mm}^{2}$ (trial 2), dual inoculations of $D$. eres $+D$. brevicancria nov. produced an intermediate relative mean lesion area of 44.93 (trial 1) and $95.25 \mathrm{~mm}^{2}$ (trial 2), and D. eres produced the smallest relative mean lesion area of 11.98 (trial 1) and $15.23 \mathrm{~mm}^{2}$ (trial 2). According to Tukey's honestly significant difference test, all treatments were significantly different from each other and the control (Fig. 5A and $5 \mathrm{~B})$. There was no significant relationship between stem diameter 
and lesion area in the two trials when lesion sizes produced by $D$. brevicancria nov. isolates $(P=0.364$ and 0.731$)$, D. eres isolates $(P=0.199$ and 0.098$)$, and dual inoculations $(P=0.526$ and 0.423$)$ were compared. Block effects were not detected in the two trials ( $P=0.153$ and $P=0.948$, respectively). Data were normally distributed in the first trial and the second trial (Shapiro-Wilk test; $P=0.848$ and $P=0.902$, respectively) after $\log$ transformation, and variances between lesion sizes for the inoculation treatments in the two trials were homogeneous (Levene's test; $P=0.097$ and $P=0.318$, respectively).

\section{Taxonomy}

Diaporthe brevicancria nov. Sakalidis, M.L. Medina-Mora, C.M.

MycoBank: MB834661

Figure 4, Supplementary Figures S9 and S10

Holotypus: CBS 146962, Michigan Isolate Fungal Culture Collection (MIFCC) 313, P82

Etymology: From the Latin words brev (shallow) and cancria (cankered), referring to the production of numerous often nonresinous cankers just below the bark layer of infected trees. Cankers do not appear to penetrate beyond the phloem into the sapwood and are therefore considered shallow.

Pycnidia on PDA and on CBS branches on WA often appear with 4 weeks of mycelial growth, $298 \pm$ SE 10 (236 to 368) $\mu \mathrm{m}$ in diameter, dark brown to black, globose, and within host tissue, papillate with elongated necks, solitary or aggregated, unilocular or multilocular, often with creamy yellow conidial cirrus exuding from ostiole (Fig. 4A and B). Conidiomata often and rapidly get covered with mycelium, usually singular or in aggregates. Conidiophores are hyaline and ampulliform (Fig. 4D and H). Conidiogenous cells are phialidic and narrowing toward the apex (Fig. 4I). Phialides are 7.1 to $17.5(11.5) \mu \mathrm{m}$ long (SD 2.5, $n=30$ ) and 1.0 to $2.4(1.7) \mu \mathrm{m}$ wide (SD, $0.3 ; n=30$ ) (Fig. 4J). Alpha conidia are 4.4 to $8.6(6.7) \mu \mathrm{m}$ long (SD, $0.9 ; n=150)$ and 1.3 to 3.3 (1.9) $\mu \mathrm{m}$ wide (SD, $0.2 ; n=$ 150), abundant in culture and on CBS branches and CBS needles on WA, hyaline, aseptate, oblong to ellipsoid, often biguttulate, with a subtruncated base (Fig. 4E, F, and K). Beta conidia are 12.4 to 27.4 (19.0) $\mu \mathrm{m}$ long (SD, 3.3; $n=50$ ) and 0.9 to 2.1 (1.5) $\mu \mathrm{m}$ wide (SD, 0.3; $n=50$ ), aseptate, hyaline, smooth, mostly convex at one end; corniform to hamate (i.e., hooked), falcate to fusiform, with a subtruncated base, and abundantly formed in culture and on CBS branches and needles (Fig. 4E, G, and K). Gamma conidia are absent.

On average, the alpha conidia of $D$. brevicancria nov. are slightly thicker and longer than the alpha conidia of $D$. eres, and slightly shorter and thinner than the alpha conidia of D. maritima (Table 4). Beta conidia of $D$. brevicancria nov., D. eres, and D. maritima overlap in length and width, except the beta conidia of $D$. maritima (DAOMC250563) were slightly wider. In culture, D. brevicancria nov. strains produced copious amounts of hamous or hooked beta conidia, whereas $D$. eres and $D$. maritima produced falcate beta conidia, as previously described by Udayanga et al. (2014a) and Tanney et al. (2016), respectively.

Notes: All three isolates (MIFCC 305, MIFCC 308, and MIFCC 313 ) of $D$. brevicancria nov. produced pycnidia in culture and copious amounts of alpha and beta conidia embedded in a yellow cirrhi (Fig. 4B). Under the cultural conditions reported in this study, isolate MIFCC 305 produced more alpha conidia than beta conidia, and its conidia were slightly shorter than the conidia produced by isolates MIFCC 308 and MIFCC 313. Overall, MIFCC 308 and MIFCC 313 produced more beta conidia than alpha conidia (Table 4). Sexual structures (perithecia, asci, and ascospores) were not seen in planta and in culture. The D. eres isolate MIFCC 320 produced more alpha conidia than the $D$. eres isolate MIFCC 306, and its production of beta conidia in planta and in culture were not observed. Under the cultural conditions reported in this study, asexual spores for the D. eres isolate MIFCC 316 were not observed (Table 4), because of either unfavorable conditions or loss of capacity to produce pycnidia in planta and in culture after recovery from long-term storage.

Cultural characteristics: In a $18 / 6 \mathrm{~h}$ photoperiod at approximately $22^{\circ} \mathrm{C}$, colonies growing on PDA of fluffy mycelia are light when immature to dark greenish gray as they mature (GLEY $17 / 10 Y ; n=3$ ), alternating light and dark shades in concentric rosulate circles, mostly lighter at the edge of the colony and darker toward the center, reverse dark greenish gray to greenish black in color (GLEY 1 4/5G_/1 to GLEY 1 2.5/5GY), and often rosulate circles can be observed (Fig. 4C and Supplementary Fig. S9). Mycelia in 2\% malt extract agar appear to be less fluffy in comparison with its growth on PDA. Maximum growth on PDA occurs at $25^{\circ} \mathrm{C}$ (range from growth trial with SD and $n=6$ for each strain), with limited growth at 15 and $30^{\circ} \mathrm{C}$ and no growth at $4,10,35$, and $40^{\circ} \mathrm{C}$.

Notes: Colony growth on the PDA media of the isolates of $D$. eres and $D$. brevicancria nov. was significantly affected by temperature $(P<0.0001)$ (Supplementary Fig. S10). The isolates of $D$. eres grew between 10 and $35^{\circ} \mathrm{C}$, and the isolates of $D$. brevicancria nov. grew between 15 and $30^{\circ} \mathrm{C}$. Optimal mycelial growth occurred at $25^{\circ} \mathrm{C}$ for all isolates (MIFCC 305, MIFCC 308, and MIFCC 313) of D. brevicancria nov. and at 20 to $25^{\circ} \mathrm{C}$ (isolates MIFCC 306 and MIFCC 316) and 20 to $30^{\circ} \mathrm{C}$ (isolate MIFCC 320 ) for $D$. eres isolates.

Host: D. brevicancria nov. isolated from the margin of bark cankers on lower branches of an adult tree of $P$. pungens, August 2012 (holotype CBS 146962; MIFCC 313), P. glauca 'Densata,' and $P$. abies.

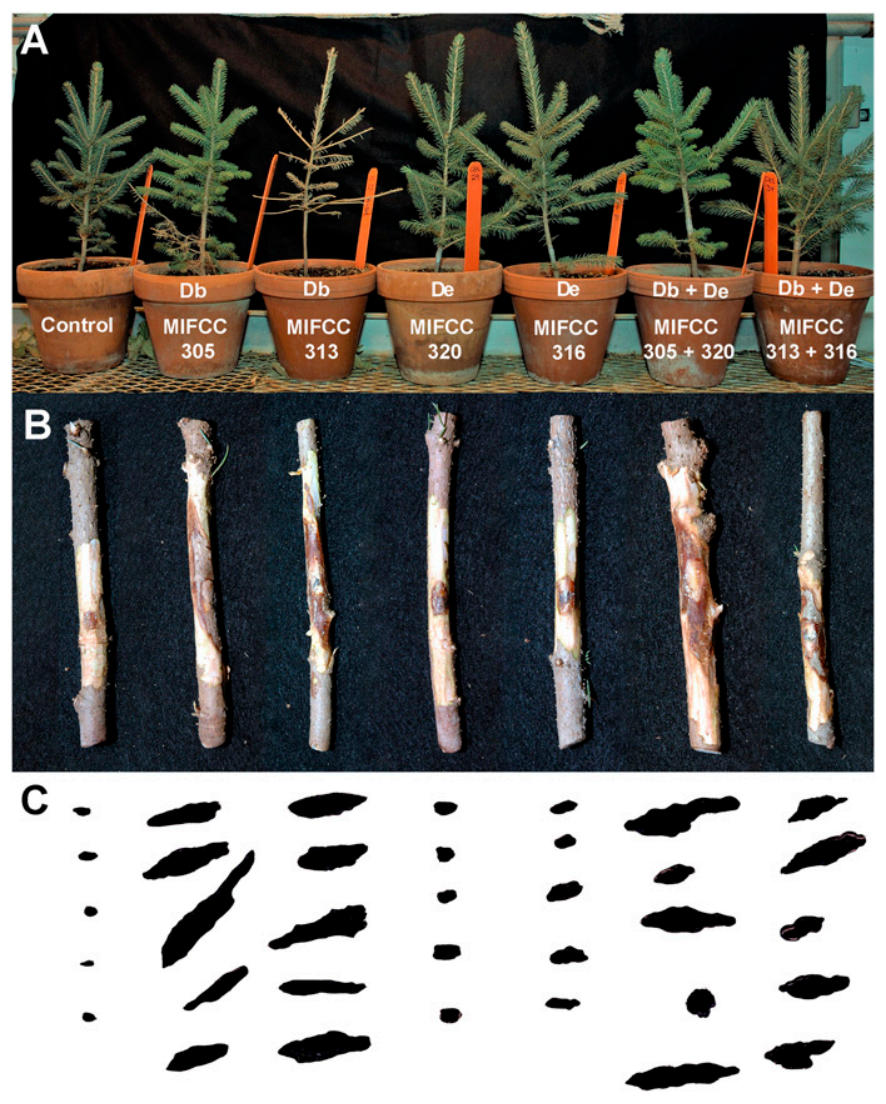

Fig. 3. Representative symptoms of Colorado blue spruce (Picea pungens) seedlings inoculated with Diaporthe brevicancria nov. (Db; MIFCC 305 and MIFCC 313), Diaporthe eres (De; MIFCC 320 and MIFCC 316), and mixed isolates (MIFCC $305+$ MIFCC 320 and MIFCC $313+$ MIFCC 316), or potato dextrose agar (control) from pathogenicity trial 1 : A, needle chlorosis, needle loss, and branch dieback; B, lesions visible under the bark; and $\mathbf{C}$, lesion tracings that were used for lesion area calculation. 
Distribution: Michigan (Lower Peninsula), USA.

Diagnosis: D. brevicancria nov., previously included in the $D$. eres species complex, is classified as moderately virulent on P. pungens (McTavish et al. 2018), where it produces larger cankers than $D$. eres. Genetically, D. brevicancria nov. is closely related to D. maritima (Tanney et al. 2016), D. bicincta (Udayanga et al. 2014a), and D. celastrina (Udayanga et al. 2014a), but morphologically it differs in the abundant production of beta conidia in vivo and in culture. D. maritima (Tanney et al. 2016) produces antifungal and
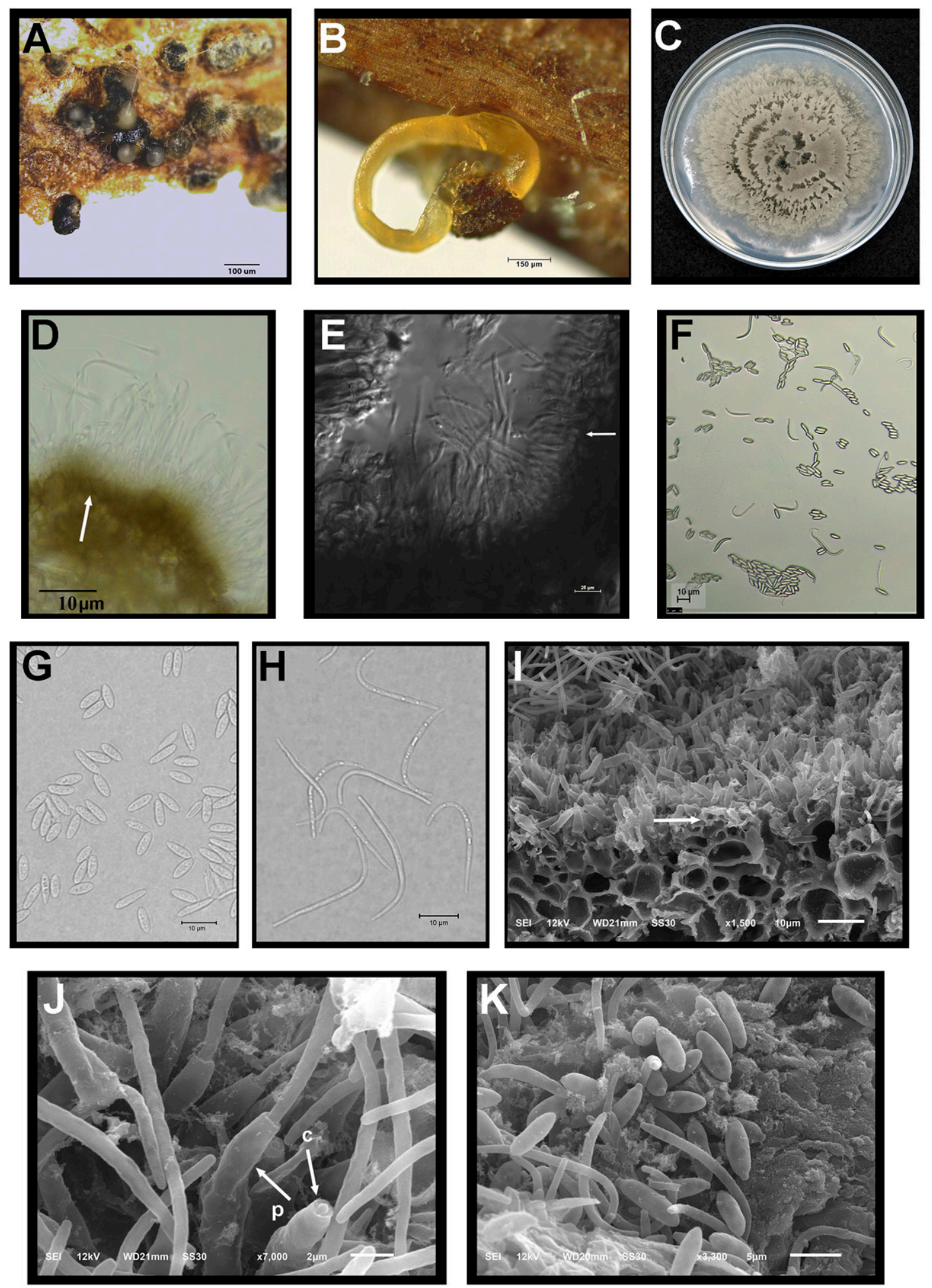

Fig. 4. Morphological characteristics of Diaporthe brevicancria nov. A, Pycnidia on excised stem of Colorado blue spruce (Picea pungens) 5 weeks after inoculation with $D$. brevicancria nov. (MIFCC 313); B, conidial cirrhus emerging from pycnidium present on a 30-day-old colony on spruce needle embedded on $1.8 \%$ water agar; $\mathbf{C}, 10$-day-old culture on potato dextrose agar; $\mathbf{D}$, conidiophores; $\mathbf{E}$, oblong alpha conidia and filiform beta conidia; $\mathbf{F}$, oblong alpha conidia; $\mathbf{G}$, filiform beta conidia; $\mathbf{H}$, differential interference contrast micrograph of phialidic conidiophores. I, Scanning electron microscope micrographs of phialidic conidiogenous cells; J, phialides ("p") with flaring collarettes ("c"); and $\mathbf{K}$, alpha and beta conidia. 
antibacterial exudates in culture, characteristics not investigated for $D$. brevicancria nov. in this study.

\section{DISCUSSION}

Two species of Diaporthe, D. eres and a new species, D. brevicancria nov. (described in this article), are associated with declining CBS in nursery, landscape, and abandoned Christmas tree plantations in Michigan. Both species produce cankers on CBS seedlings that lead to needle loss and branch dieback consistent with symptoms that are observed on mature spruce throughout the lower peninsula of Michigan. D. brevicancria nov. produces stem lesions that are significantly larger than those produced by $D$. eres. Dual

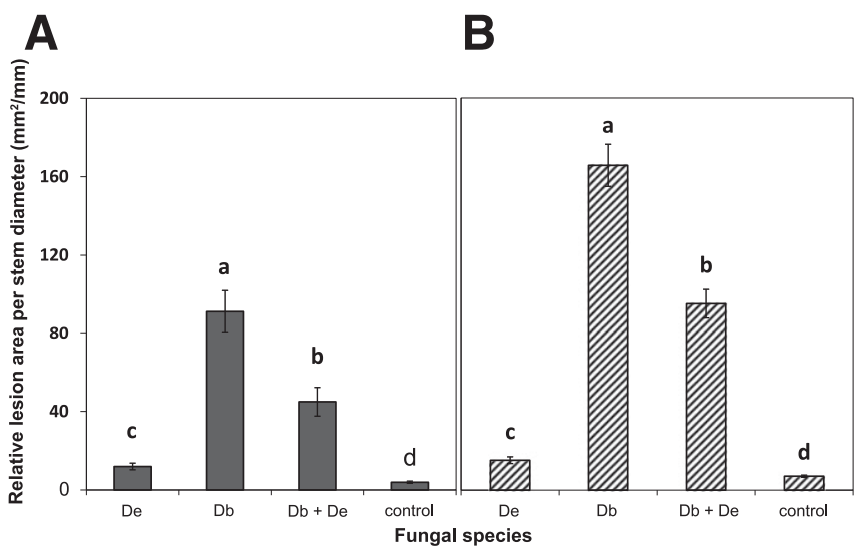

Fig. 5. Mean lesion areas of Colorado blue spruce (Picea pungens) seedlings inoculated with Diaporthe brevicancria nov. (Db; MIFCC 305 and MIFCC 313), Diaporthe eres (De; MIFCC 320 and MIFCC 316), and mixed isolates (MIFCC 305 + MIFCC 320 and MIFCC 313 + MIFCC 316), or agar (control): A, Results after 12 weeks, experiment 1 (single site of inoculation per plant); and $\mathbf{B}$, results after 5 weeks, experiment 2 (two sites of inoculation per plant). Bars represent the standard error of the mean $(n=5)$. Bars labeled with same letter are not significantly different between the treatments and experiments at $P<0.05$ via Tukey's honestly significant difference test. inoculations of both species produced stem lesions significantly larger than those of $D$. eres and control inoculations but significantly smaller than inoculations only with $D$. brevicancria nov. Both species have been isolated from symptomatic $P$. pungens and P. glauca (McTavish et al. 2018; this study). D. brevicancria nov. has also been isolated from symptomatic P. abies (McTavish et al. 2018; this study). Additional hosts of $D$. eres include Pseudotsuga menziesii and Thuja occidentalis (McTavish et al. 2018).

Dissanayake (2017) circumscribed a total of 171 species of Diaporthe, where D. celastrina, D. bicincta, and D. maritima formed a monophyletic clade. In this study, D. brevicancria nov. was genetically indistinguishable from its sister species, D. maritima, in the calmodulin gene region. However, six other gene regions (betatubulin, DNA lyase, elongation factor 1-alpha, internal transcribed spacer region, histone-3, and partial sequences of actin) were able to resolve $D$. brevicancria nov. as a species. D. brevicancria nov. was genetically most similar to $D$. maritima, followed by $D$. bicincta, then D. celastrina. These three species have been reported in North America and are associated with asymptomatic Picea rubens (Canada) and with symptomatic Juglans sp. (United States and Canada) and Celastrus sp. (United States), respectively (Tanney et al. 2016; Udayanga et al. 2014a).

Recent work that has focused on the $D$. eres clade suggests that D. eres is paraphyletic (Dissanayake 2017; Udayanga et al. 2014a), forming at least two clades. It is likely that $D$. eres will continue to be refined and cryptic species added as further studies focus on using genetic relationships to assist in species delimitation. When considered as a single species, $D$. eres appears to be genetically diverse and cosmopolitan and has a broad host range. The $D$. eres isolated from conifers in this study were most closely related to isolate CBS 439.82 (syn. D. cotoneastri [Punith.]), collected from Cotoneaster sp. in Scotland (Udayanga et al. 2012). Other isolates that are genetically similar to CBS 439.82 have been collected from Ulmus sp., Cornus florida, Oxydendrum arboretum, Sassafras albidum, and Juglans cinerea in the United States (Fig. 2 in Udayanga et al. 2014a). The $D$. eres isolated in this study has been isolated only from coniferous hosts, and it is unclear whether the Michigan D. eres can

TABLE 4. Pycnidia and conidia characteristics of Diaporthe brevicancria nov. produced in vitro (grown on potato dextrose agar at $22^{\circ} \mathrm{C}$ ) in comparison with other Diaporthe species

\begin{tabular}{|c|c|c|c|c|c|c|c|}
\hline \multirow[b]{3}{*}{ Species } & \multirow[b]{3}{*}{ Isolate code } & \multicolumn{6}{|c|}{ Morphological measurements ${ }^{\mathrm{a}}$} \\
\hline & & \multirow[b]{2}{*}{ Pycnidia } & \multicolumn{5}{|c|}{ Conidia } \\
\hline & & & Alpha & $\alpha(\mu \mathrm{m})$ & Beta & $\beta(\mu \mathrm{m})$ & Gamma \\
\hline \multirow[t]{3}{*}{ D. brevicancria nov. } & MIFCC $305^{\mathrm{b}}$ & + & ++ & $4.5-7.8 \times 1.8-3.2$ & + & $11.5-24.9 \times 1-2$ & - \\
\hline & MIFCC $308^{b}$ & + & + & $4.6-8.6 \times 1.3-3.3$ & ++ & $16-31.8 \times 0.9-1.9$ & - \\
\hline & MIFCC $313^{\mathrm{b}}$ & + & + & $4.4-8.2 \times 1.3-3.3$ & ++ & $11.2-24 \times 0.6-1.3$ & - \\
\hline \multirow[t]{3}{*}{ D. eres } & MIFCC $306^{\mathrm{b}}$ & + & + & $4-6.8 \times 1.3-2.3$ & + & $12.4-27.4 \times 1-2$ & - \\
\hline & MIFCC $316^{\mathrm{b}}$ & $\mathrm{n} / \mathrm{o}$ & - & $\mathrm{n} / \mathrm{o}$ & - & $\mathrm{n} / \mathrm{o}$ & - \\
\hline & MIFCC $320^{\mathrm{b}}$ & + & ++ & $4.5-7.8 \times 1.8-3.2$ & - & $\mathrm{n} / \mathrm{o}$ & - \\
\hline \multirow[t]{2}{*}{$=$ Phomopsis cotoneastri } & & + & $\mathrm{n} / \mathrm{r}$ & $6-9 \times 2$ & $\mathrm{n} / \mathrm{r}$ & $18-25 \times 1$ & $-^{\mathrm{c}}$ \\
\hline & CBS439.82 & + & ++ & $6-9 \times 3-4$ & $\mathrm{v}$ & $18-29 \times 1-1.5$ & $-^{\mathrm{d}}$ \\
\hline \multirow[t]{2}{*}{ D. maritima } & NB36571I ${ }^{\mathrm{b}}$ & + & ++ & $4.4-9.5 \times 1-2$ & + & $11.2-32 \times 1.5-3.5$ & - \\
\hline & NB36571I & $\mathrm{v}$ & $\mathrm{n} / \mathrm{r}$ & $10-13.5 \times 3-4$ & $\mathrm{n} / \mathrm{r}$ & $32-40 \times 1-2$ & $-^{\mathrm{e}}$ \\
\hline D. bicincta & CBS121004 & $\mathrm{n} / \mathrm{r}$ & ++ & $9-12 \times 2-3.5$ & - & $\mathrm{n} / \mathrm{o}$ & $-\mathrm{d}$ \\
\hline D. celastrina & CBS139.27 & $\mathrm{n} / \mathrm{r}$ & $\mathrm{v}$ & $9-12 \times 2-3.5$ & - & $\mathrm{n} / \mathrm{o}$ & $-^{\mathrm{d}}$ \\
\hline Phomopsis conorum & & $\mathrm{n} / \mathrm{r}$ & $\mathrm{n} / \mathrm{r}$ & $6.2-15 \times 2.5-4$ & $\mathrm{n} / \mathrm{r}$ & $10-34 \times 1$ & $\mathrm{n} / \mathrm{r}^{\mathrm{f}}$ \\
\hline \multirow[t]{2}{*}{ D. occulta } & & $\mathrm{n} / \mathrm{r}$ & $\mathrm{n} / \mathrm{r}$ & $6-8 \times 2-2.5$ & $\mathrm{n} / \mathrm{r}$ & $15-34.5$ & $+^{\mathrm{g}}$ \\
\hline & & + & + & $6.2-8.8 \times 2-2.6$ & + & $28.3-22.3 \times 1-1.2$ & $\mathrm{n} / \mathrm{r}^{\mathrm{h}}$ \\
\hline
\end{tabular}

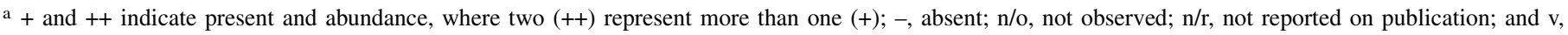
variable.

b Data generated in the current study.

c Punithalingam (1973).

d Udayanga et al. (2014a).

e Tanney et al. (2016).

f Hahn (1928).

g Hahn (1930)

h Sanderson and Worf (1986). 
also colonize a broader taxonomic range of host species; certainly, a broad host range would increase the capacity for pathogen spread.

D. brevicancria nov. is morphologically indistinguishable from D. eres and D. maritima. Colony characteristics overlap, with the three species forming fluffy light to dark greenish gray mycelia, and brown to black pycnidia that are scattered, singular, or aggregated on PDA. The sizes of asexual spores among D. eres, D. maritima, and $D$. brevicancria nov. also overlap. However, the alpha conidia of D. maritima were on the larger end of the range observed. D. eres, $D$. brevicancria nov., and D. maritima all produce beta conidia, whereas the closely related $D$. bicincta and $D$. celastrina do not produce beta conidia. On the basis of published cultural criteria, D. bicincta is the only species where paraphyses have been reported as present in culture (Udayanga et al. 2014a), whereas paraphyses in D. celastrina, D. cotoneastri (Punithalingam 1973; Udayanga et al. 2014a), D. eres, and D. maritima (Tanney et al. 2016) are absent or have not been seen in culture. Gamma spores, which were reported to be present on Phomopsis (= Diaporthe) occulta isolated from hemlock (Hahn 1930), are not present in D. eres, D. brevicancria nov., D. maritima, D. cotoneastri, or D. bicinta. Multiple attempts were made to obtain perithicia of $D$. eres and $D$. vadumcanri in planta or on CBS branches embedded on water agar. However, sexual structures were not observed in our study.

Unlike other Diaporthe spp. that have been associated with resinous cankers on conifers (Boyce 1933; Igoe et al. 1995), the Diaporthe spp. isolated from declining CBS in Michigan appear to produce dry, nondescript cankers. Previous reports have linked Diaporthe spp. to shoot blight and stem cankers of CBS in nurseries in Wisconsin and Michigan (Igoe et al. 1995; Sanderson and Worf 1986) and in landscape trees in Wisconsin and Michigan (McTavish et al. 2018; Sanderson and Worf 1986). The Diaporthe spp. isolated in our study are morphologically different from $P$. occulta that was isolated from nursery and landscape CBS in Wisconsin (Sanderson and Worf 1986; Table 4 in this study). It is not possible to determine whether the $D$. eres isolated from nursery CBS in Michigan in 1995 is the same as those associated with declining CBS at present, because no spore measurements were reported in the study. However, it is clear that both $D$. eres and D. brevicancria nov. have been present in symptomatic conifers in nursery, landscape, and abandoned Christmas tree plantations in Michigan since 2011 (McTavish et al. 2018; this study).

Diaporthe is a large genus encompassing $>860$ species that may be endophytic, saprophytic, or pathogenic depending on the host colonized and the health status of that host (Gomes et al. 2013). It is not clear how Diaporthe on conifers in the Midwest, particularly on CBS, become infected with Diaporthe, nor is it clear how these Diaporthe spp. spread. The life cycle of Diaporthe associated with CBS has not been characterized. We occasionally observe pycnidia of Diaporthe forming on senesced shoot ends that are bent toward the ground, commonly known as a shepherd's crook, but this phenomenon is not common. In greenhouse inoculation trials we observed pycnidia forming around inoculation points, but we have not observed pycnidia on cankers in naturally infected trees. Crous and Groenewald (2005) suggested that fungal pathogens that are virulent on a single host may have the capacity to asymptomatically colonize alternative hosts as endophytes, where the alternative hosts serve as a stepping stone or a "pogo stick" that would enable further dispersal of the fungus. These hosts may facilitate the propagules (i.e., spores) of the fungus encountering a susceptible host, to which the fungus is virulent, and the fungal life cycle could be completed; this is known as the pogo stick hypothesis. Both $D$. eres and D. brevicancria nov. were isolated from cankers on several species of conifers. The closely related $D$. maritima was isolated as an endophyte from $P$. rubens (Tanney et al. 2016). It is possible that $D$. eres and $D$. brevicancria nov. have the capacity to asymptomatically colonize alternative hosts as endophytes and then sporulate as saprophytes on senescent tissues of these hosts. This may increase the spread and survival of Diaporthe spp. until a susceptible host is encountered, where disease could develop and a larger number of fungal propagules be dispersed. It is also possible that Diaporthe spp. may act as latent pathogens, in which case they could colonize a susceptible host where the host remains asymptomatic for a period of time, until the host experiences additional stressors, which may then result in disease expression. This endophytic life stage could increase the ability of the fungus to spread, unnoticed, to additional hosts and geographic regions. Additional research into the host range, endophytic potential, and epidemiology of Diaporthe spp. infecting conifers in the Midwest would assist in managing this disease.

In greenhouse settings, $D$. brevicancria nov. appears to be more virulent toward CBS than D. eres. McTavish et al. (2018) identified multiple haplotypes of Diaporthe that demonstrated variable virulence against several coniferous hosts. McTavish et al. (2018) reported that haplotypes 1 and 3 (identified as isolates MIFCC 316 and 306 of $D$. eres in our study) produced cankers significantly smaller than those of haplotypes 2, 4, and 5 (now identified as isolates MIFCC 305, 308, and 313 of D. brevicancria nov.). Furthermore, McTavish et al. (2018) indicated that P. meyeri, P. omorika, P. glauca 'Densata,' P. glauca, P. abies, and CBS have increasing levels of susceptibility to disease caused by $D$. brevicancria nov. with minimal impact from $D$. eres. Of these spruce species, $D$. brevicancria nov. has been isolated from symptomatic CBS, $P$. abies, and $P$. glauca but has not yet been isolated from $P$. meyeri, $P$. omorika, or $P$. glauca 'Densata,' supporting the greenhouse pathogenicity trial conclusions that these three species may be resistant or tolerant to disease caused by Diaporthe.

In our study, we increased the inoculum dosage in our second pathogenicity trial, effectively doubling the amount of inoculum introduced into the seedling. This resulted in a substantial increase in lesion area around the $D$. brevicancria nov. inoculation site and a small increase in lesion area around the $D$. eres inoculation site. Because of the increase in dosage, we anticipated that we would see an increase in lesion area and symptom development in a shorter period of time than with a lower pathogen load. The small increase in lesion size of $D$. eres and substantial increase in lesion size of $D$. brevicancria nov. suggests that $D$. eres is less virulent then $D$. brevicancria nov. in $P$. pungens seedlings.

Extending the virulence findings of our greenhouse study to the landscape-level disease issue may be premature. Our greenhouse studies suggest that $D$. eres is a minor antagonist, yet this species was isolated from declining landscape spruce. It is clear that the environmental component of the disease triangle has not yet been accounted for in this disease complex. Decline is a result of predisposing (climate, site factors, tree genetics), inciting (weather, anthropogenic influences), and contributing factors (pests and pathogens) (Manion 1981; Sinclair and Hudler 1988). In the spruce decline system, it is likely that some type of chronic abiotic stress has driven the Diaporthe canker epidemic in genetically susceptible trees. Changes in the Michigan climate over the last 20 years have resulted in an increase in the average minimum temperature and precipitation in April to June and an increase in the average maximum temperature and decrease in precipitation July to October (Dai et al. 2016). This increase has led to warmer, wet springs that may be conducive to pathogen sporulation and infection and drier, hotter summers and falls that may lead to host stress. These climatic trends combined with anthropological influences such as pollution, density, and high frequency of spruce plantings in the 1970s and 1980s may have compounded host stress and created favorable conditions for pathogen proliferation (i.e., a large quantity of susceptible food source, sufficient moisture, and protection from the elements for reproduction and infection, because of the high moisture and shade created from tree branches growing into each other). Sanderson and Worf (1986) demonstrated that high temperatures and humidity resulted in more disease in CBS. However, data regarding current abiotic stressors on these trees are limited. Identifying the contributing and inciting factors of this 
decline are critical to managing currently declining trees and making decisions about the possibility of propagating and planting new CBS. Certainly, future avenues of research may include collecting weather, soil, and site data at symptomatic sites coupled with growth chamber trials to test environmental influences such as plant density, moisture availability, and temperature.

Not all CBS in the landscape appear to be affected by spruce decline, because healthy, symptomless trees are often observed adjacent to diseased trees. This finding suggests that CBS have varying resistance to Diaporthe. It is also possible that there is variation in the virulence of isolates of each species. Indeed, in greenhouse trials there was some variation in susceptibility to Diaporthe, although no seedling inoculated with Diaporthe remained entirely symptomless. Obtaining seed from symptomless trees in areas of high disease pressure may provide a source of resistant or partially resistant germplasm for future tree breeding research. We found that dual inoculations of $D$. brevicancria nov. and D. eres in the greenhouse experiment resulted in moderately sized cankers, suggesting that $D$. eres reduces the ability of $D$. brevicancria nov. to cause disease. This reduction may be caused by physical competition between coexisting pathogens in the same host for growth- and fitness-limiting resources or chemical competition between those producing toxic compounds (Abdullah et al. 2017). From naturally occurring infections, there has only been a single incidence of both species being isolated from different branches of the same CBS tree in 2018 (our study). It was more common to isolate either $D$. eres or D. brevicancria nov. from symptomatic trees rather than both on one tree. Other species of Diaporthe are known to cooccur on the same host or lesion (Brayford 1990; Crous and Groenewald 2005; Farr et al. 2002; Gomes et al. 2013; Mostert et al. 2001; Rehner and Uecker 1994). Additional surveys may examine the incidence of co-occurrence of $D$. eres and D. brevicancria nov. and associated disease severity in CBS. Certainly, our current efforts to develop a molecular assay for direct detection of $D$. eres and D. brevicancria nov. from woody tissues may assist in determining whether both species can occupy the same individual tree.

The incidence of symptomatic spruce associated with Diaporthe canker may be underestimated. It is possible that the canker symptoms associated with Diaporthe infection are often missed in diagnosis, probably because of the inconspicuous nature of the cankers (evident only when the bark layer is removed) and also because samples that are sent into diagnostic labs often consist of the terminal 12 inches or less of the branch, and it is possible that cankers present further back along the branch cannot be assessed (J. Byrne, personal communication). The MSU Plant \& Pest Diagnostics lab has diagnosed Phomopsis blight, dieback, and canker from plants in the Juniperus, Picea, Abies, and Thuja genera. D. juniperivora (syn. Phomopsis juniperova) was associated with several symptomatic Juniperus spp. samples. However, it is unclear which Diaporthe spp. was associated with the remainder of the samples. Greater awareness of Diaporthe spp. as canker causing pathogens on conifers may provide a more accurate reflection of the impact these pathogens have at the landscape level beyond Michigan.

This study has shown that the fungal pathogens $D$. eres and $D$. brevicancria nov. have the ability to cause cankers that contribute to the widespread decline of mature landscape spruce across Michigan. It is likely that spruce decline occurs beyond Michigan. It is possible that needle loss and branch dieback symptoms have been solely attributed to a range of needle cast diseases instead of the canker causing Diaporthe spp., as was the case in Michigan for some time. It is critical to establish the extent of declining spruce, determine the role Diaporthe plays, and develop testable hypotheses to elucidate the drivers of the decline.

\section{ACKNOWLEDGMENTS}

We thank Jill O'Donnell for her observations, advice, and sample collection; the researchers who have contributed to spruce decline research over the last 8 years (Gabdiel Yulfo-Soto, Jan Wulff, Mayra Velén Buendia Velazquez, Chrissy McTavish, Mursel Catal, Sara Stadt, and Andrew M. Jarosz); the staff at MSU's Center for Advance Microscopy; Douglas H. Minier for technical assistance with differential interference contrast and scanning electron microscopy; and Konstanze Bensch from MycoBank for providing assistance with the Latin nomenclature for our new species.

\section{LITERATURE CITED}

Abdullah, A. S., Moffat, C. S., Lopez-Ruiz, F. J., Gibberd, M. R., Hamblin, J., and Zerihun, A. 2017. Host-multi-pathogen warfare: Pathogen interactions in co-infected plants. Front. Plant Sci. 8:1806.

Abramoff, M. D., Magalhães, P. J., and Ram, S. J. 2004. Image processing with ImageJ. Biophoton. Int. 11:36-42.

Anagnostakis, S. L. 2007. Diaporthe eres (Phomopsis oblonga) as a pathogen of butternut (Juglans cinerea) in Connecticut. Plant Dis. 91:1198.

Baumgartner, K., Fujiyoshi, P. T., Travadon, R., Castlebury, L. A., Wilcox, W. F., and Rolshausen, P. E. 2013. Characterization of species of Diaporthe from wood cankers of grape in eastern North American vineyards. Plant Dis. 97:912-920.

Boddy, L., and Griffith, G. 1989. Role of endophytes and latent invasion in the development of decay communities in sapwood of angiospermous trees. Sydowia 41:41-73.

Boyce, J. S. 1933. A canker of Douglas fir associated with Phomopsis canker. J. For. 31:664-672.

Brayford, D. 1990. Variation in Phomopsis isolates from Ulmus species in the British Isles and Italy. Mycol. Res. 94:691-697.

Butler, G., Rasmussen, M. D., Lin, M. F., Santos, M. A. S., Sakthikumar, S., Munro, C. A., et al. 2009. Evolution of pathogenicity and sexual reproduction in eight Candida genomes. Nature 459:657-662.

Carroll, G. 1986. The biology of endophytism in plants with particular reference to woody perennials. Pages 205-222 in: Microbiology of the Phyllosphere. N. J. Fokkema and J. van den Heuvel, eds. Cambridge University Press, Cambridge, U.K.

Crous, P. W., and Groenewald, J. Z. 2005. Hosts, species and genotypes: Opinions versus data. Australas. Plant Pathol. 34:463.

Dai, S., Shulski, M. D., Hubbard, K. G., and Takle, E. S. 2016. A spatiotemporal analysis of Midwest US temperature and precipitation trends during the growing season from 1980 to 2013. Int. J. Climatol. 36:517-525.

Darriba, D., Taboada, G. L., Doallo, R., and Posada, D. 2012. jModelTest 2: More models, new heuristics and parallel computing. Nat. Methods 9:772.

Di Tommaso, P., Moretti, S., Xenarios, I., Orobitg, M., Montanyola, A., Chang, J.-M., Taly, J.-F., and Notredame, C. 2011. T-Coffee: A web server for the multiple sequence alignment of protein and RNA sequences using structural information and homology extension. Nucleic Acids Res.: W13-W17.

Dissanayake, A. 2017. The current status of species in Diaporthe. Mycosphere 8:1106-1156.

Fan, X. L., Hyde, K. D., Udayanga, D., Wu, X. Y., and Tian, C. M. 2015. Diaporthe rostrata, a novel ascomycete from Juglans mandshurica associated with walnut dieback. Mycol. Prog. 14:82.

Farr, D. F., Castlebury, L. A., Rossman, A. Y., and Putnam, M. L. 2002. A new species of Phomopsis causing twig dieback of Vaccinium vitis-idaea (lingonberry). Mycol. Res. 106:745-752.

Felsenstein, J. 1985. Confidence intervals on phylogenetics: an approach using bootstrap. Evolution (N. Y.) 39:783-791.

Freedman, A. H., Schweizer, R. M., Ortega-Del Vecchyo, D., Han, E., Davis, B. W., Gronau, I., Silva, P. M., Galaverni, M., Fan, Z., Marx, P., Lorente-Galdos, B., Ramirez, O., Hormozdiari, F., Alkan, C., Vilà, C., Squire, K., Geffen, E., Kusak, J., Boyko, A. R., Parker, H. G., Lee, C., Tadigotla, V., Siepel, A., Bustamante, C. D., Harkins, T. T., Nelson, S. F., Marques-Bonet, T., Ostrander, E. A., Wayne, R. K., and Novembre, J. 2016. Demographically-based evaluation of genomic regions under selection in domestic dogs. PLoS Genet. 12:e1005851.

Fulbright, D. W., Catal, M., Stadt, S., and O'Donnell, J. 2011a. Spruce tree problem shows symptoms of both needlecast and branch death. MSU Ext News. https://www.canr.msu.edu/news/spruce_tree_problem_shows_symptoms_of_both_needlecast_and_branch_death

Fulbright, D. W., Mursel, C., Stadt, S., and O'Donnell, J. 2011b. Spruce problems are probably caused by more than a single agent. MSU Ext. News. https://www.canr.msu.edu/news/spruce_problems_are_probably_caused_by_ more_than_a_single_agent

Fulbright, D. W., and O'Donnell, J. 2011. What's going on with blue spruce? MSU Ext. News. https://www.canr.msu.edu/news/whats_going_on_with_ blue_spruce

Fulbright, D. W., Stadt, S., and O'Donnell, J. 2012. Michigan awash with Phomopsis cankers on spruce trees and seedlings. MSU Ext. News. https:// www.canr.msu.edu/news/michigan_awash_with_phomopsis_cankers_on_ spruce_trees_and_seedlings 
Gardes, M., and Bruns, T. D. 1993. ITS primers with enhanced specificity for basidiomycetes: Application to the identification of mycorrhizae and rusts. Mol. Ecol. 2:113-118.

Glass, N. L., and Donaldson, G. C. 1995. Development of primer sets designated for use with the PCR to amplify conserved regions from filamentous ascomycetes. Appl. Environ. Microbiol. 61:1323-1330.

Gomes, R. R., Glienke, C., Videira, S. I. R., Lombard, L., Groenewald, J. Z., and Crous, P. W. 2013. Diaporthe: a genus of endophytic, saprobic and plant pathogenic fungi. Persoonia Mol. Phylogeny Evol. Fungi. 31:1-41.

Guindon, S., and Gascuel, O. 2003. A simple, fast, and accurate algorithm to estimate large phylogenies by maximum likelihood. Syst. Biol. 52:696-704.

Hahn, G. G. 1928. Life-history studies of the species of Phomopsis occurring on conifers. Part I. Trans. Brit. Mycol. Soc. 15:32-93.

Hahn, G. G. 1930. Life-history studies of the species of Phomopsis occurring in conifers, Part I. Trans. Br. Mycol. Soc. 15:32-93, IN1-IN3.

Hamelin, R. C., Bourassa, M., Rail, J., Dusabenyagasani, M., Jacobi, V., and Laflamme, G. 2000. PCR detection of Gremmeniella abietina, the causal agent of scleroderris canker of pine. Mycol. Res. 104:527-532.

Hillis, D. M., and Huelsenbeck, J. P. 1992. Signal, noise and reliability in molecular phylogenetic analysis. J. Hered. 83:189-195.

Huang, F., Udayanga, D., Wang, X., Hou, X., Mei, X., Fu, Y., Hyde, K. D., and Li, H. 2015. Endophytic Diaporthe associated with citrus: A phylogenetic reassessment with seven new species from China. Fungal Biol. 119: 331-347.

Igoe, M., Peterson, N., and Roberts, D. 1995. A Phomopsis canker associated with branch dieback of Colorado blue spruce in Michigan. Plant Dis. 79: 202-205.

Manion, P. D. 1981. Tree Disease Concepts. Prentice-Hall Inc., Englewood Cliffs, NJ.

McTavish, C. K., Catal, M., Fulbright, D. W., and Jarosz, A. M. 2018. Spruce decline and Diaporthe: Incidence, taxonomy, virulence, and tree susceptibility in Michigan. Plant Dis. 102:2330-2340.

Michigan Department of Agriculture and USDA National Agricultural Statistics Service (MDARD \& and USDA NASS). 2005. Pages 2004-2005 in: Michigan Rotational Survey, Nursery and Christmas Trees. USDA, NASS, Michigan Field Office, Lansing, MI.

Miller, M. A., Pfeiffer, W., and Schwartz, T. 2010. Creating the CIPRES Science Gateway for inference of large phylogenetic trees. Pages 1-8 in: 2010 Gateway Computing Environments Workshop (GCE). IEEE, New York.

Moretti, S., Armougom, F., Wallace, I. M., Higgins, D. G., Jongeneel, C. V., and Notredame, C. 2007. The M-Coffee web server: A meta-method for computing multiple sequence alignments by combining alternative alignment methods. Nucleic Acids Res. W645-W648.

Mostert, L., Crous, P., Kang, C.-J., and Phillips, A. 2001. Species of Phomopsis and a Libertella sp. occurring on grapevines with specific reference to South Africa: morphological, cultural, molecular and pathological characterization. Mycologia 93:146-166.

Notredame, C., Higgins, D. G., and Heringa, J. 2000. T-coffee: A novel method for fast and accurate multiple sequence alignment. J. Mol. Biol. 302:205-217.

Punithalingam, E. 1973. Two new species of Phomopsis. Trans. Br. Mycol. Soc. 60:157-160.

Rehner, S. A., and Uecker, F. A. 1994. Nuclear ribosomal internal transcribed spacer phylogeny and host diversity in the coelomycete Phomopsis. Can. J. Bot. 72:1666-1674.

Ronquist, F., Teslenko, M., van der Mark, P., Ayres, D. L., Darling, A., Höhna, S., Larget, B., Liu, L., Suchard, M. A., and Huelsenbeck, J. P. 2012. MrBayes 3.2: Efficient Bayesian phylogenetic inference and model choice across a large model space. Syst. Biol. 61:539-542.

Sanderson, P. G., and Worf, G. L. 1986. Phomopsis shoot blight of Colorado blue spruce. J. Environ. Hortic. 4:134-138.
Santos, J., and Phillips, A. 2009. Resolving the complex of Diaporthe (Phomopsis) species occurring on Foeniculum vulgare in Portugal. Fungal Divers. 34:111-125.

Santos, J. M., Vrandečić, K., Ćosić, J., Duvnjak, T., and Phillips, A. J. L. 2011. Resolving the Diaporthe species occurring on soybean in Croatia. Persoonia Mol. Phylogeny Evol. Fungi. 27:9-19.

Santos, L., Alves, A., and Alves, R. 2017. Evaluating multi-locus phylogenies for species boundaries determination in the genus Diaporthe. PeerJ 5: e3120.

Sinclair, W., and Hudler, G. 1988. Tree declines: Four concepts of causality. J. Arboric. 14:29-35

Stamatakis, A. 2014. RAxML version 8: A tool for phylogenetic analysis and post-analysis of large phylogenies. Bioinformatics 30:1312-1313.

Stöver, B. C., and Müller, K. F. 2010. TreeGraph 2: Combining and visualizing evidence from different phylogenetic analyses. BMC Bioinformatics 11:7.

Swofford, D. L. 2002. PAUP* Phylogenetic Analysis Using Parsimony (*and other methods). Version 4. Sinauer Associates, Sunderland, MA.

Tanney, J. B., McMullin, D. R., Green, B. D., Miller, J. D., and Seifert, K. A. 2016. Production of antifungal and antiinsectan metabolites by the Picea endophyte Diaporthe maritima sp. nov. Fungal Biol. 120:1448-1457.

Thomidis, T., and Michailides, T. J. 2009. Studies on Diaporthe eres as a new pathogen of peach trees in Greece. Plant Dis. 93:1293-1297.

Thompson, S. M., Tan, Y. P., Young, A. J., Neate, S. M., Aitken, E. A. B., and Shivas, R. G. 2011. Stem cankers on sunflower (Helianthus annuиs) in Australia reveal a complex of pathogenic Diaporthe (Phomopsis) species. Persoonia Mol. Phylogeny Evol. Fungi. 27:80-89.

Udayanga, D., Castlebury, L. A., Rossman, A. Y., Chukeatirote, E., and Hyde, K. D. 2014a. Insights into the genus Diaporthe: Phylogenetic species delimitation in the D. eres species complex. Fungal Divers. 67:203-229.

Udayanga, D., Castlebury, L. A., Rossman, A. Y., and Hyde, K. D. 2014b. Species limits in Diaporthe: molecular re-assessment of D. citri, D. cytosporella, D. foeniculina and D. rudis. Persoonia 32:83-101.

Udayanga, D., Liu, X., Crous, P. W., McKenzie, E. H. C., Chukeatirote, E., and Hyde, K. D. 2012. A multi-locus phylogenetic evaluation of Diaporthe (Phomopsis). Fungal Divers. 56:157-171.

Udayanga, D., Liu, X., McKenzie, E. H. C., Chukeatirote, E., Bahkali, A. H. A., and Hyde, K. D. 2011. The genus Phomopsis: Biology, applications, species concepts and names of common phytopathogens. Fungal Divers. 50:189-225.

Uecker, F. 1988. A world list of Phomopsis names with notes on nomenclature, morphology and biology. Mycol. Mem. 13:1-231.

van Rensburg, J. C. J., Lamprecht, S. C., Groenewald, J. Z., Castlebury, L. A., and Crous, P. W. 2006. Characterisation of Phomopsis spp. associated with die-back of rooibos (Aspalathus linearis) in South Africa. Stud. Mycol. 55: 65-74.

Vrandečić, K., Jurković, D., and Ćosić, J. 2010. Phomopsis vrste na vinovoj lozi uistočnoj hrvatskoj [Phomopsis species on grapevine in eastern Croatia, in Croatian]. Glas. Biljn. Zaštite. 4:246-252.

Wade, C. A. 2010. Ecological change in the urban forest of six Midwest, USA cities over twenty-five years. Ph.D. dissertation, Michigan State University, East Lansing, MI

Wallace, I. M., O’Sullivan, O., Higgins, D. G., and Notredame, C. 2006. MCoffee: Combining multiple sequence alignment methods with T-Coffee. Nucleic Acids Res. 34:1692-1699.

Webber, J. F., and Gibbs, J. N. 1984. Colonization of elm bark by Phomopsis oblonga. Trans. Br. Mycol. Soc. 82:348-352.

White, T. J., Bruns, T., Lee, S., and Taylor, J. 1990. Amplification and direct sequencing of fungal ribosomal RNA genes for phylogenetics. Pages 315-322 in: PCR Protocols, a Guide to Methods and Applications. M. Innis, D. Gelfand, J. Shinsky, and T. White, eds. Academic Press, Waltham, MA. 